\title{
Effect of heat-treatment temperature after polymer melt and blending ratio on the crystalline structure of PVDF in a PVDF/PMMA blend
}

\author{
Hideo Horibe ${ }^{1}$, Yukari Hosokawa ${ }^{1}$, Hironori Oshiro ${ }^{1}$, Yasutaka Sasaki ${ }^{1}$, Seiji Takahashi ${ }^{1}$, Akihiko Kono ${ }^{1}$, \\ Takashi Nishiyama ${ }^{1}$ and Tetsuya Danno ${ }^{2}$
}

We analyzed control of the crystalline structure of poly(vinilydene fluoride) (PVDF) in a PVDF/poly(methylmethacrylate) (PMMA) blend by varying the polymer blend ratio (PVDF/PMMA $=60 / 40,70 / 30$ and $80 / 20 \mathrm{wt} \%$ ) and the heat-treatment temperature $\left(160-210^{\circ} \mathrm{C}\right.$ ) just after the polymer melt. We obtained PVDF (form I) limitedly by heat treatment at 185 and $190^{\circ} \mathrm{C}$ after blending PVDF/PMMA 70/30 wt\%. The samples produced under other conditions indicated PVDF (form II). Results of differential scanning calorimetry (DSC), polarized light micrography and light transmittance indicated that samples of PVDF/ PMMA 70/30 wt \% heat-treated at 185 and $190{ }^{\circ} \mathrm{C}$ exhibited high compatibility between PVDF and PMMA, respectively. In contrast, PVDF (form II) samples obtained in other conditions indicated lower compatibility. We assumed that PVDF crystalline structure became the structure of the PVDF (form I) according to decrease of the crystallization rate by the highest compatibility between PVDF and PMMA. Pure PVDF crystallized very fast, so PVDF (form I) cannot be developed from pure PVDF by simply controlling the heat-treatment temperature.

Polymer Journal (2013) 45, 1195-1201; doi:10.1038/pj.2013.53; published online 26 June 2013

Keywords: blend ratio; compatibility; crystalline structure; polymer blend; poly(methylmethacrylate); poly(vinylidene fluoride)

\section{INTRODUCTION}

The three crystalline structures in poly(vinilydene fluoride) (PVDF) exist as PVDF (form I), PVDF (form II) and PVDF (form III). ${ }^{1}$ PVDF (form I) has superior electric characteristics (for example, piezoelectricity and pyroelectricity) based on the polarity between hydrogen $(\delta+)$ and fluorine $(\delta-){ }^{2}$ The polymer chains of PVDF (form I) are in a distorted, planar zigzag, all-trans conformation, and the unit cell is polar. The intramolecular interaction energy of PVDF (form I) is $-0.48 \mathrm{kcal} \mathrm{mol}^{-1}$ m.u., and that of PVDF (form II) is $-1.46 \mathrm{kcal} \mathrm{mol}^{-1} \mathrm{~m} . \mathrm{u}$. The intermolecular interaction energy of PVDF (form I) is $-5.25 \mathrm{kcal} \mathrm{mol}^{-1}$ molecular unit (m.u.) and that of PVDF (form II) is $-4.57 \mathrm{kcal} \mathrm{mol}^{-1} \mathrm{~m}$.u. On the basis of these data, the total potential energy of PVDF (form I) is $-5.73 \mathrm{kcal} \mathrm{mol}^{-1}$ m.u. and that of PVDF (form II) is $-6.03 \mathrm{kcal} \mathrm{mol}^{-1} \mathrm{~m} . \mathrm{u}$. Therefore, PVDF (form II) is generally more stable than PVDF (form I). ${ }^{3,4}$ It is necessary to produce PVDF (form I) under severe conditions (for example, applying strong electric field). Owing to the importance of PVDF that has piezoelectricity and pyroelectricity, we have attempted many methods to produce PVDF (form I) ${ }^{5-9}$ We previously reported our production of PVDF by controlling the drying temperature after solvent casting from a single solvent. When the drying temperature was higher, PVDF (form II) was obtained; when the drying temperature was lower, PVDF (form I) was obtained; and when the drying temperature was at mid-level, PVDF (form III) was obtained. PVDF (form I) may be produced because of the slow crystallization of PVDF. $^{9}$ PVDF (high crystalline polymer) and poly(methylmethacrylate) (PMMA; amorphous polymer) is a very rare combination that exhibits compatibility in a blend. ${ }^{10-18}$ Some mixtures exhibit very complex behavior, gradually shifting to a phaseseparation state, to a compatible state and then to a phase-separation state with heating. A part of crystalline polymer and amorphous polymer demonstrates compatibility. The mixture is compatible in the melt state (near the melting point) and is in a phase-separation state below the melting-point temperature $\left(T_{\mathrm{m}}\right) \cdot{ }^{19}$ The melting-point depression phenomenon and the drop of the crystallinity are caused by amorphous polymer in the amorphous phase of crystalline polymer. Moreover, in many cases, amorphous phases against composition of blended polymer indicate the single glass-transition temperature $\left(T_{\mathrm{g}}\right)$, which is represented by Fox's equation ${ }^{20}$ and Gordon-Taylor's equation. ${ }^{21}$ We reported in our previous study that PVDF (form I) is obtained by heat treatment for 1 day at $120^{\circ} \mathrm{C}$ with quenching after hot-press with PVDF/PMMA blend ratio 70:30 wt\%. ${ }^{22-27}$

In case of pure PVDF, PVDF became cloudy, although PVDF was quenched just after the hot-press, without heat treatment, and it

${ }^{1}$ Research Laboratory for Integrated Technological Systems, Kanazawa Institute of Technology, Hakusan, Japan and ${ }^{2}$ Faculty of Human Life and Environmental Science, University of Kochi, Kochi, Japan

Correspondence: Professor H Horibe, Research Laboratory for Integrated Technological Systems, Kanazawa Institute of Technology, 3-1 Yatsukaho, Hakusan 924-0838, Japan. E-mail: hhoribe@neptune.kanazawa-it.ac.jp

Received 14 March 2013; revised 5 May 2013; accepted 9 May 2013; published online 26 June 2013 
formed crystal conformation of PVDF (form II). This result indicates rapid crystallization speed of $\mathrm{PVDF}^{25}$ Therefore, we assume that the formation of PVDF (form I) with a PVDF/PMMA blend is strongly affected by the compatibility of PVDF and PMMA. Thus, the crystalline structure of PVDF can be controlled when the compatibility of PVDF and PMMA changes with the heat-treatment temperature at the instant PVDF and PMMA are blended. In this study, we demonstrated the control of the PVDF crystalline structures changing by polymer blend ratio and the heat-treatment temperatures after polymer melt.

\section{EXPERIMENTAL PROCEDURE}

Materials and sample preparation

PVDF (KYNAR K720, by Arkema, Tokyo, Japan) was used in this experiment. PMMA (HBS000, by Mitsubishi Rayon Co., Ltd., Tokyo, Japan) was used. We obtained PVDF/PMMA (blend ratios of 60/40, $70 / 30$ and $80 / 20 \mathrm{wt} \%$ ) with a melt-blend of $5 \mathrm{~min}$ using a labo plast mill (4M150, by Toyo Seiki Seisaku-sho, Tokyo, Japan) at $200{ }^{\circ} \mathrm{C}$ and 80 r.p.m. After milling, we hot-pressed the samples at $200^{\circ} \mathrm{C}$ and $45 \mathrm{MPa}$ for $5 \mathrm{~min}$. We then immediately placed the melted samples in the oven, where they were annealed for 1 day at 160,170,180, 185 and $190{ }^{\circ} \mathrm{C}$. Those with a PVDF/PMMA ratio of 70/30 wt $\%$ were also annealed at 200 and $210^{\circ} \mathrm{C}$. After heat treatment, each sample was quenched by cold water in order to instantly fix the crystalline structure. In addition, we compared each blend ratio sample with a pure PVDF sample made, using the methods described above. For the sake of simplicity, we indicate a PVDF/PMMA blend ratio of $x /(100-x)($ wt $\%)$ as F $x$ hereafter. For example, F70 $(\mathrm{F} x, x=70)$ was used to refer to a PVDF/PMMA blend ratio of 70/30 wt $\%$, and F100 $(\mathrm{F} x, x=100)$ to refer to $100 / 0 \mathrm{wt} \%$.

\section{Sample evaluations}

We used X-ray diffraction (XRD; Rigaku Corporation, Tokyo, Japan, $30 \mathrm{kV}, 15 \mathrm{~mA}$, MiniFlex II) and Fourier transform infrared spectroscopy (FT-IR; Shimadzu Corporation, Kyoto, Japan, Prestige-21) to evaluate the crystalline structure of the produced sample. As the XRD parameter, the $\mathrm{Cu}-\mathrm{k} \alpha$-ray (wavelength $1.54 \AA$ ) was used as X-ray. The scan speed was $2.0^{\circ} \mathrm{min}^{-1}$, and the measuring range was $10^{\circ} \leqslant 2 \theta$ $\leqslant 50^{\circ}$. For FT-IR measurements, the wave number range was 700 $1500 \mathrm{~cm}^{-1}$ using attenuated total reflection (PIKE Technologies, WI, USA, MIRacle). The melting-point and the $T_{\mathrm{g}}$ of the samples were measured at a sample weight of $5 \mathrm{mg}$ and a programming rate of $10{ }^{\circ} \mathrm{Cmin}^{-1}$ using differential scanning calorimetry (DSC; Rigaku, DSC8230). A polarizing microscope (Nikon Corporation, Tokyo, Japan, LV100POL) was used to observe the spherulite state of the samples. The light transmittance of the samples were measured from 200 to $800 \mathrm{~nm}$ using a spectrophotometer (Shimadzu, UV-2450). Sample thicknesses were $0.4-0.5 \mathrm{~mm}$; thus, we revised the data by adapting Lambert-Beer's law as if the sample thicknesses were $0.5 \mathrm{~mm}$.

\section{RESULTS AND DISCUSSION}

Production of three types of crystalline structure of PVDF as standard samples and identification

Tashiro et al. ${ }^{28}$ reported that three types of crystalline structure of PVDF were obtained using different solvents in solvent casting. They concluded that PVDF (form I) is obtained using hexamethylphosphoamide solvent, PVDF (form II) is obtained using acetone solvent and PVDF (form III) is obtained using dimethylacetamide solvent. Therefore, we produced three types of crystalline structures of PVDF, following their methods as standard samples.

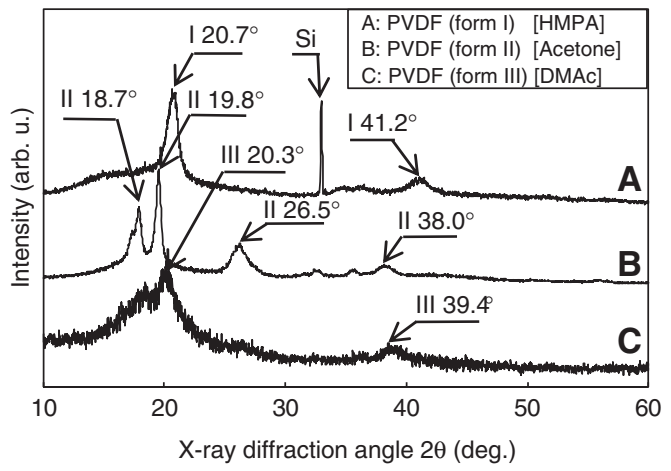

Figure 1 X-ray diffraction (XRD) spectrum of the three types of crystalline structures of poly(vinilydene fluoride) (PVDF), produced by hexamethylphosphoamide (HMPA), acetone and dimethylacetamide (DMAc) solvents.

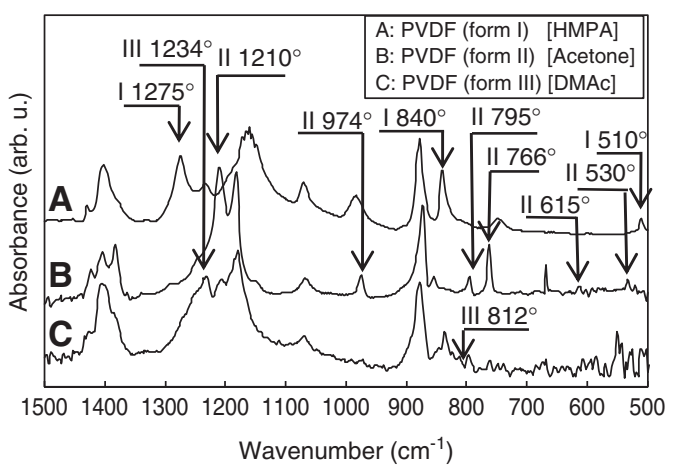

Figure 2 Attenuated total reflection (ATR) Fourier transform infrared (FT-IR) spectra of the three types of crystalline structures of poly(vinilydene fluoride) (PVDF), produced by hexamethylphosphoamide (HMPA), acetone and dimethylacetamide (DMAc) solvents.

Figure 1 depicts the XRD spectrum of three types of crystalline structures of PVDF produced using different solvents in solvent casting. PVDF (form I) indicates 20.7 and $41.2^{\circ}$ as unique peaks in the XRD spectrum. The $20.7^{\circ}$ peak corresponds to the reflective surface of (200) and (110). The $41.2^{\circ}$ peak corresponds to the reflective surface of (201) and (111). PVDF (form II) has unique peaks of $18.7,19.8,26.5$ and $38.0^{\circ}$ in the XRD spectrum. The XRD peak of $18.7^{\circ}$ corresponds to the reflective surface of $(020), 19.8^{\circ}$ corresponds to that of $(110), 26.5^{\circ}$ corresponds to that of $(021)^{29,30}$ and $38.0^{\circ}$ corresponds to that of (002). PVDF (form III) has unique peaks of 20.3 and $39.4^{\circ}$ in the XRD spectrum. The $20.3^{\circ}$ peak corresponds to the reflective surface of $(101),{ }^{31}$ and the $39.4^{\circ}$ peak corresponds to that of (401) and (132).

Figure 2 presents the attenuated total reflection FT-IR spectrum of three types of crystalline structures of PVDF produced using different solvents in solvent casting. PVDF (form I) indicates unique peaks of 510,840 and $1275 \mathrm{~cm}^{-1}$ in the infrared spectrum. ${ }^{32,33}$ The $840-\mathrm{cm}^{-1}$ peak is attributed to $\mathrm{CH}_{2}$ in-plane deformation vibration. The $510-\mathrm{cm}^{-1}$ peak is attributed to the C-F stretching vibration of PVDF (form I). PVDF (form II) has unique peaks of 530, 615, 766, 795,974 and $1210 \mathrm{~cm}^{-1}$. The $974-\mathrm{cm}^{-1}$ peak is attributed to $\mathrm{CH}_{2}$ torsional vibration. The $766-\mathrm{cm}^{-1}$ peak is attributed to the C-F stretching vibration of PVDF (form II). PVDF (form III) has unique peaks of 812 and $1234 \mathrm{~cm}^{-1}$. 
From the results of XRD and FT-IR, we can clearly obtain PVDF (form I), (form II) and (form III) by using hexamethylphosphoamide, acetone and dimethylacetamide solvents, respectively, in solvent casting. We evaluated the crystalline structures of samples that were produced in our study by comparing them with the standard samples produced using solvent casting. In the Result sections, we will indicate XRD spectrums of each sample, because XRD is the best method to determine each crystalline structure. About FT-IR spectra of each sample, we will report only on each data of infrared peak that was obtained from the infrared spectrum of each sample because there is a limitation on the amount of figures.

Crystalline structures of F60 and F70 samples with varied heattreatment temperatures immediately after melting

Figures 3, 4 present the XRD spectrum of F60, F70 samples having good compatibility that were treated at each heat-treatment temperature immediately after melting. PVDF (form II) was confirmed in the samples treated at 160,170 and $180^{\circ} \mathrm{C}$ by observing the samples' XRD peaks of $18.7^{\circ}, 19.8^{\circ}, 26.5^{\circ}$ and $38.0^{\circ}$. The XRD spectrum of the sample at $185^{\circ} \mathrm{C}$ indicated only halo diffraction without sharp peaks attributed to the crystalline structures. The XRD spectrum of the sample at $190^{\circ} \mathrm{C}$ indicated the unique peaks of PVDF (form II) again. However, these peak intensities were generally lower than that of the sample (between $160^{\circ} \mathrm{C}$ and $180^{\circ} \mathrm{C}$ ).

In FT-IR spectrum of F60 samples at each heat-treatment temperature, samples heat-treated at 160,170 and $180^{\circ} \mathrm{C}$ indicated peaks at 766, 795, 974 and $1210 \mathrm{~cm}^{-1}$, which indicates PVDF (form

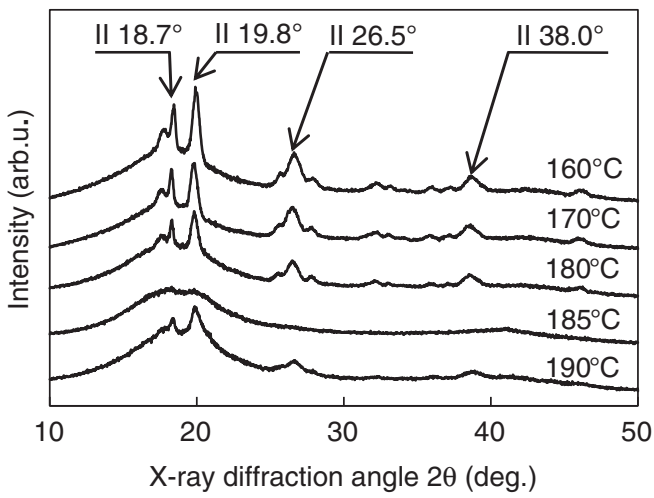

Figure 3 X-ray diffraction (XRD) spectrum of F60 samples of each heattreatment temperature immediately after melting.

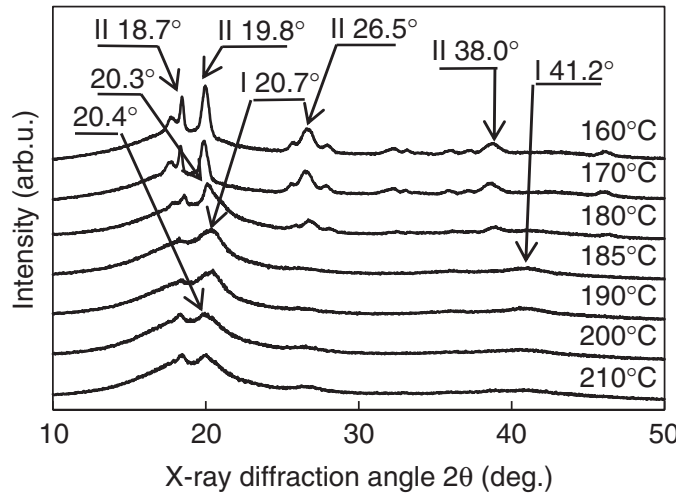

Figure 4 X-ray diffraction (XRD) spectra of F70 samples at each heattreatment temperature immediately after melting.
II). With heat-treatment temperatures of 185 and $190{ }^{\circ} \mathrm{C}$, we observe 840 and $1275 \mathrm{~cm}^{-1}$ peaks, which indicate PVDF (form I).

On the basis of the results of the XRD and the FT-IR spectrum, F60 samples at $160,170,180$ and $190^{\circ} \mathrm{C}$ indicated PVDF (form II). The sample at the heat-treatment temperature of $185^{\circ} \mathrm{C}$ is formed from amorphous structure including only a small amount of PVDF (form I). The production of PVDF (form II) at 160 and $170{ }^{\circ} \mathrm{C}$ can explain from that high crystallization rate caused by phase separation between PVDF and PMMA, which tends to occur at temperatures below the $T_{\mathrm{m}}$ of PVDF $\left(170^{\circ} \mathrm{C}\right)$. PVDF and PMMA are compatibilized at some degree about sample of the heat-treatment temperature $185^{\circ} \mathrm{C}$ because the heat-treatment temperature was sufficiently higher than the $T_{\mathrm{m}}$ of PVDF. Therefore, at $185^{\circ} \mathrm{C}$ the sample formed had almost amorphous structure as confirmed by the crystallization rate that was suppressed according to the compatibility of PVDF and PMMA. With a heat-treatment temperature of $190^{\circ} \mathrm{C}$, we considered that PVDF (form II) generated according to phase separation occurred between PVDF and PMMA again because the heattreatment temperature was quite high.

Next, we will discuss about the crystalline structures of F70. Figure 4 depicts the XRD spectra of F70 samples treated at each heat-treatment temperature immediately after melting. PVDF (form II) was confirmed in the samples treated at 160 and $170^{\circ} \mathrm{C}$ by observing the samples' XRD peaks of $18.7^{\circ}, 19.8^{\circ}, 26.5^{\circ}$ and $38.0^{\circ}$. For the sample treated at $180^{\circ} \mathrm{C}$, we observed peaks that were attributed to the crystalline structure of PVDF (form II) in the XRD spectrum. However, the $19.8^{\circ}$ peak shifted to $20.3^{\circ}$ and broadened to a high reflection angle. In addition, all peak intensities in this XRD spectrum became weaker. The heat-treated samples at 185 and $190{ }^{\circ} \mathrm{C}$ indicated 20.7 and $41.2^{\circ}$ peaks, corresponding to PVDF (form I) in the XRD spectrums. For the samples heat-treated at 200 and $210^{\circ} \mathrm{C}$, the $20.7^{\circ}$ peak that corresponded to PVDF (form I) shifted to $20.4^{\circ}$, which is a low reflection angle. These peaks exhibited halo diffraction and weakened.

From the FT-IR spectra of F70 samples at each heat-treatment temperature, we obtained the following results discussed below. For samples at the heat-treatment temperatures of 160 and $170{ }^{\circ} \mathrm{C}$, we observed 766, 795, 974 and $1210 \mathrm{~cm}^{-1}$ peaks, which indicated PVDF (form II). For heat-treatment temperatures of 180,185 and $190^{\circ} \mathrm{C}$, we observed 840 and $1275 \mathrm{~cm}^{-1}$ peaks, which indicated PVDF (form I). For the samples heat-treated at 200 and $210^{\circ} \mathrm{C}$, we observed 766,795 , 974 and $1210 \mathrm{~cm}^{-1}$ peaks, indicating PVDF (form II) again.

The XRD and FT-IR spectra for the F70 samples indicated the PVDF structures obtained at different heat-treatment temperatures, as indicated below. PVDF (form II) was produced with the heat-treated F70 samples at $170^{\circ} \mathrm{C}$. PVDF (form II) including PVDF (form I) was produced at $180^{\circ} \mathrm{C}$. PVDF (form I) was produced at 185 and $190^{\circ} \mathrm{C}$. Finally, amorphous polymer including only a little crystalline structure of PVDF (form I) and (form II) was produced at 200 and $210^{\circ} \mathrm{C}$.

Compatibility and phase separation of F70 samples with varied heat-treatment temperatures immediately after melting

We will do the detailed discussion on F70 that indicated PVDF (form I). We evaluated the compatibility and phase separation of F70 samples with varied heat-treatment temperatures immediately after melting using DSC, polarizing microscopy and spectrophotometry. Figure 5 indicates the DSC measurements of F70 samples at each heat-treatment temperature immediately after melting, and Table 1 indicates the $T_{\mathrm{m}}$ and $T_{\mathrm{g}}$ of samples that were obtained from DSC results at each heat-treatment temperature. The samples heat-treated 
at $160,170,180,185,190,200$ and $210^{\circ} \mathrm{C}$ had melting points of 169 , $169,166,166,166,167$ and $167^{\circ} \mathrm{C}$. The heat-treated samples at 180 , 185 and $190^{\circ} \mathrm{C}$ indicated the lowest $T_{\mathrm{m}}$ of $166^{\circ} \mathrm{C}$. In addition, $T_{\mathrm{g}}$ of the sample heat-treated at 180,185 and $190^{\circ} \mathrm{C}$ was $64^{\circ} \mathrm{C}$, and those at 200 and $210^{\circ} \mathrm{C}$ was near $50^{\circ} \mathrm{C}$. When PVDF was compatibilized with PMMA, $T_{\mathrm{g}}$ was between $-50^{\circ} \mathrm{C}\left(T_{\mathrm{g}}\right.$ of PVDF $)$ and $100^{\circ} \mathrm{C}\left(T_{\mathrm{g}}\right.$ of PMMA). ${ }^{12,13}$ Furthermore, melting-point depression of PVDF occurs

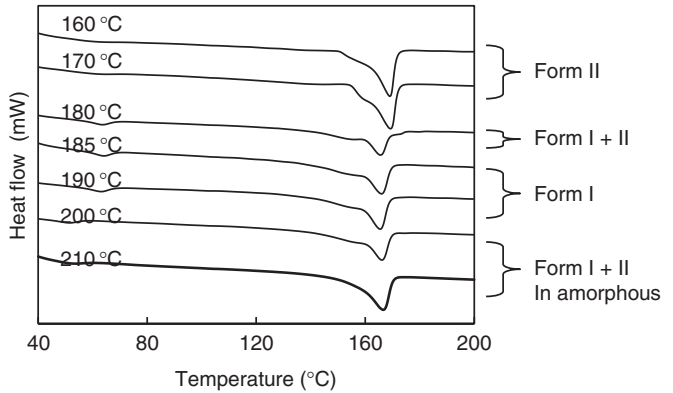

Figure 5 Differential scanning calorimetry (DSC) curves of F70 samples with varied heat-treatment temperatures immediately after melting.

Table $1 T_{\mathrm{g}}$ and $T_{\mathrm{m}}$ of $\mathrm{F} 70$ samples with varied heat-treatment temperatures

\begin{tabular}{lcc}
\hline Heat-treatment temperature $\left({ }^{\circ} \mathrm{C}\right)$ & $\mathrm{T}_{g}\left({ }^{\circ} \mathrm{C}\right)$ & $\mathrm{T}_{m}\left({ }^{\circ} \mathrm{C}\right)$ \\
\hline 160 & - & 169 \\
170 & - & 169 \\
180 & 64 & 166 \\
185 & 64 & 166 \\
190 & 64 & 166 \\
200 & 50 & 167 \\
210 & 50 & 167 \\
\hline
\end{tabular}

Abbreviations: $T_{\mathrm{g}}$, glass-transition temperature; $T_{\mathrm{m}}$, melting-point temperature. when PVDF was compatibilized with PMMA. ${ }^{19}$ The heat-treated samples at 180,185 and $190{ }^{\circ} \mathrm{C}$ indicated $T_{\mathrm{g}}$ at the middle temperature on harmonizing with PVDF and PMMA. Furthermore, good compatibility between PVDF and PMMA was confirmed because the melting point of PVDF decreased the most. The samples heat-treated at 200 and $210{ }^{\circ} \mathrm{C}$ also indicated good compatibility between PVDF and PMMA. The compatibility of these samples was inferior to that of the heat-treated samples at 180,185 and $190^{\circ} \mathrm{C}$, as the PVDF melting point exceeded 180,185 and $190^{\circ} \mathrm{C}$. PVDF (form I) was obtained limitedly in the blend ratio of F70 and at the heat-treatment temperatures of 185 and $190^{\circ} \mathrm{C}$. From DSC results, the heat-treated samples of 185 and $190^{\circ} \mathrm{C}$ had the highest compatibility between PVDF and PMMA. Therefore, PVDF (form I) was formed according to decrease of the crystallization rate, which caused a high compatibility between PVDF and PMMA, in these samples. 3,9

Figures $6 a-g$ depict the polarized light micrographs of F70 samples with varied heat-treatment temperatures immediately after melting to investigate the compatibility between PVDF and PMMA. Polarized light micrograph (a) is PVDF (form II) formed by heat treatment at $160^{\circ} \mathrm{C}$, (b) is PVDF (form II) formed by heat treatment at $170^{\circ} \mathrm{C}$, (c) is PVDF (forms I and II) formed by heat treatment at $180^{\circ} \mathrm{C}$, (d) is PVDF (form I) formed by heat treatment at $185^{\circ} \mathrm{C}$, (e) is PVDF (form I) formed by heat treatment at $190^{\circ} \mathrm{C}$, (f) is PVDF (amorphous included forms I and II) formed by heat treatment at $200{ }^{\circ} \mathrm{C}$ and (g) is PVDF (amorphous including forms I and II) formed by heat treatment at $210^{\circ} \mathrm{C}$. From these micrographs, we observed that spherulites grown densely in the heat-treated sample at $160^{\circ} \mathrm{C}$ were $30 \mu \mathrm{m}$ in diameter, and those grown at $170{ }^{\circ} \mathrm{C}$ were $40 \mu \mathrm{m}$ in diameter. The heat-treated sample at $180^{\circ} \mathrm{C}$, with 40 - $\mu$ m-diameter spherulites grew sparsely. However, no spherulites were observed in the samples heat-treated at $185,190,200$ and $210^{\circ} \mathrm{C}$. The polarized light micrographs of samples at 200 and $210^{\circ} \mathrm{C}$ had contrasts comparable to those at 185 and $190^{\circ} \mathrm{C}$. For the samples heat-treated at 160 and $170{ }^{\circ} \mathrm{C}$, we assumed that dense growth of spherulites
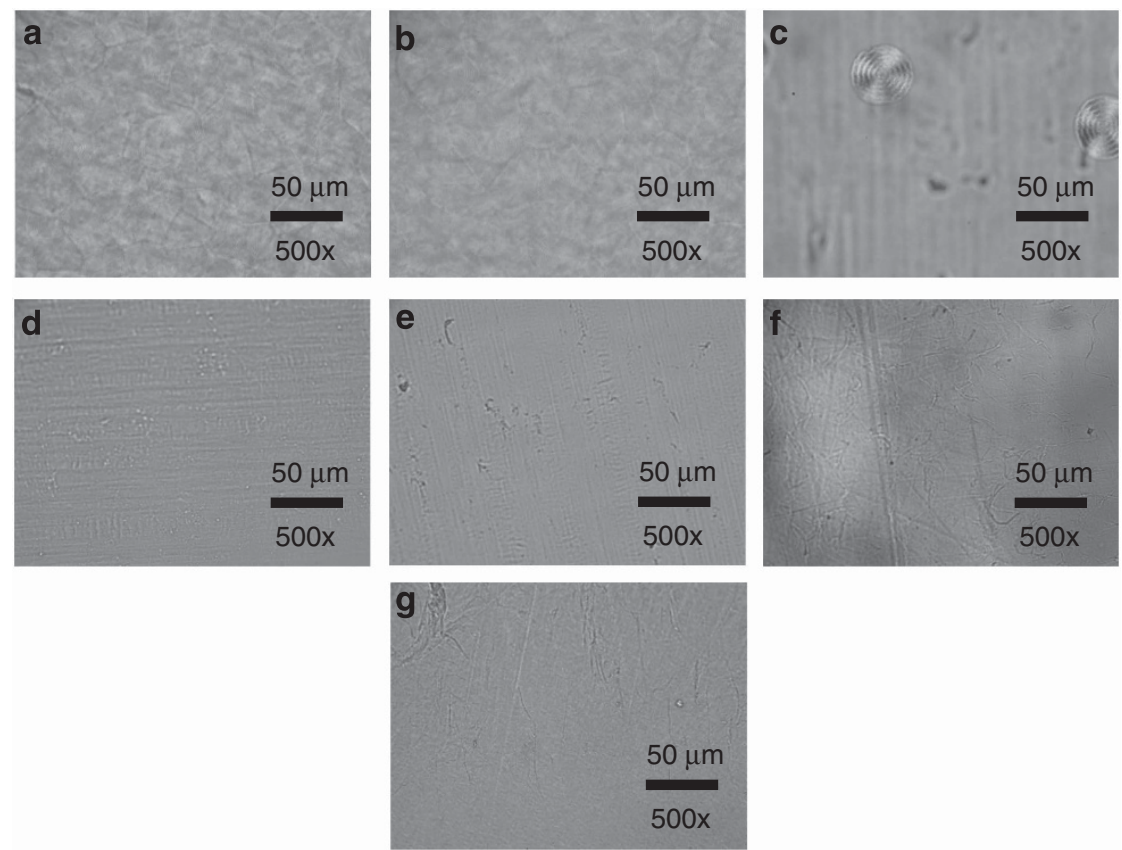

Figure 6 Polarized light micrographs of F70 samples with varied heat-treatment temperatures immediately after melting. Heat-treatment temperature of a is $160^{\circ} \mathrm{C}$, b is $170^{\circ} \mathrm{C}, \mathbf{c}$ is $180^{\circ} \mathrm{C}, \mathbf{d}$ is $185^{\circ} \mathrm{C}$, e is $190^{\circ} \mathrm{C}, \mathbf{f}$ is $200^{\circ} \mathrm{C}$ and $\mathbf{g}$ is $210^{\circ} \mathrm{C}$. A full color version of this figure is available at Polymer Journal online. 
corresponded to crystallization of PVDF by phase separation between PVDF and PMMA. The slight growth of spherulites corresponded to slight crystallization of PVDF, because compatibility between PVDF and PMMA was lower in the sample treated at $180^{\circ} \mathrm{C}$. In contrast, the crystallization of PVDF was suppressed by higher compatibility between PVDF and PMMA for the samples heat-treated at 185 and $190^{\circ} \mathrm{C}$; thus, no spherulites grew. In the samples heat-treated at 200 and $210^{\circ} \mathrm{C}$, no spherulites were observed; these samples tended to crystallize, based on the observed contrasts in the polarized light micrographs.

We investigated the ultraviolet/visible spectra of F70 samples with varied heat-treatment temperatures immediately after melting. Figure 7 indicates the light transmittance of F70 samples, and Table 2 indicates the light transmittance of $800 \mathrm{~nm}$ light of F70 samples. The light transmittance of the samples heat-treated at 160, $170,180,185,190,200$ and $210^{\circ} \mathrm{C}$ at a wavelength of $800 \mathrm{~nm}$ was $44 \%, 44 \%, 58 \%, 86 \%, 89 \%, 78 \%$ and $75 \%$, respectively. PVDF (form II) was obtained from the samples heat-treated at 160 and $170{ }^{\circ} \mathrm{C}$; therefore, we assumed that light transmittance of these samples were less influenced by light scattering corresponding to the dense growth of spherulites. We also assumed that the light transmittance of the sample heat-treated at $180^{\circ} \mathrm{C}$ was higher than that of the samples treated at 160 and $170{ }^{\circ} \mathrm{C}$, based on the increased spherulite density. The light transmittance of the samples heat-treated at 185 and $190{ }^{\circ} \mathrm{C}$ became the highest without light scattering because there were no spherulites in these samples. These samples were obtained as PVDF (form I). In the heat-treated samples at 200 and $210^{\circ} \mathrm{C}$, we considered that these samples from the polarized light micrographs, which compared with the heat-treated samples at 185 and $190^{\circ} \mathrm{C}$, had tended to crystallize partly according to the observed uneven parts.

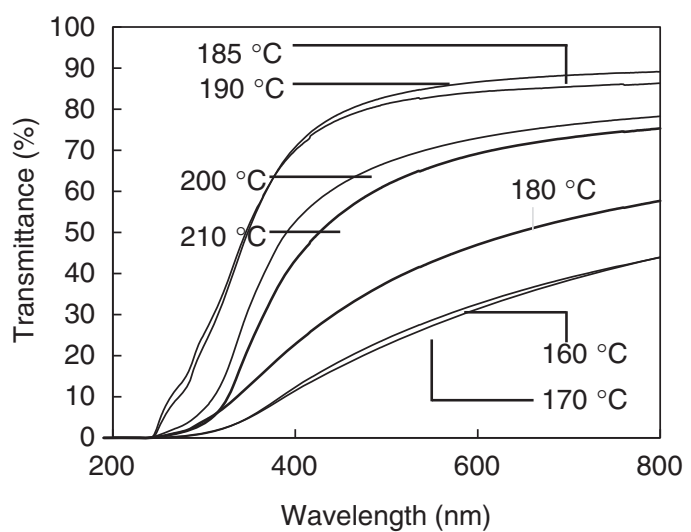

Figure 7 Light transmittance of F70 samples with varied heat-treatment temperatures immediately after melting.

Table 2 Light transmittance of $800 \mathrm{~nm}$ light of F70 samples with varied heat-treatment temperatures

\begin{tabular}{lc} 
Heat-treatment temperature $\left({ }^{\circ} \mathrm{C}\right)$ & Transmittance of $800 \mathrm{~nm}$ light (\%) \\
\hline 160 & 44 \\
170 & 44 \\
180 & 58 \\
185 & 86 \\
190 & 89 \\
200 & 78 \\
210 & 75 \\
\hline
\end{tabular}

Crystalline structures of F80 and F100 samples with varied heattreatment temperatures immediately after melting

Figure 8 depicts the XRD spectrum of F80 samples treated at each heat-treatment temperature immediately after melting. The unique peaks of PVDF (form II) were observed in the XRD spectra of all samples heat-treated at deflection angles of 18.7, 19.8, 26.5 and 38.0 . In the FT-IR spectra of the F80 samples, all FT-IR spectra also indicated the unique peaks of PVDF (form II) at wave numbers 766, 795, 974 and $1210 \mathrm{~cm}^{-1}$

From these results, PVDF (form II) was obtained at all heattreatment temperatures from 160 to $190^{\circ} \mathrm{C}$. The F80 samples became PVDF (form II) at all the treatment temperatures. PVDF (form II) was obtained by phase separation, which occurred between PVDF and PMMA abundantly, in the F80 samples.

For the F100 samples, we experimented to confirm whether PVDF (form I) can be obtained from pure PVDF with varied heat-treatment temperatures immediately after melting. Figure 9 depicts the XRD spectra of the heat-treated F100 samples at $160,185,200$ and $220^{\circ} \mathrm{C}$. XRD spectra of the heat-treated F100 samples at all heat-treatment temperatures indicated PVDF (form II) based on the unique peaks of $18.7,19.8,26.5$ and $38.0^{\circ}$. In the FT-IR spectra of the heat-treated F100 samples at $160,185,200$ and $220^{\circ} \mathrm{C}$, FT-IR spectra of the heattreated F100 sample at all heat-treatment temperatures indicated PVDF (form II) with unique peaks of 766, 795, 974 and $1210 \mathrm{~cm}^{-1}$.

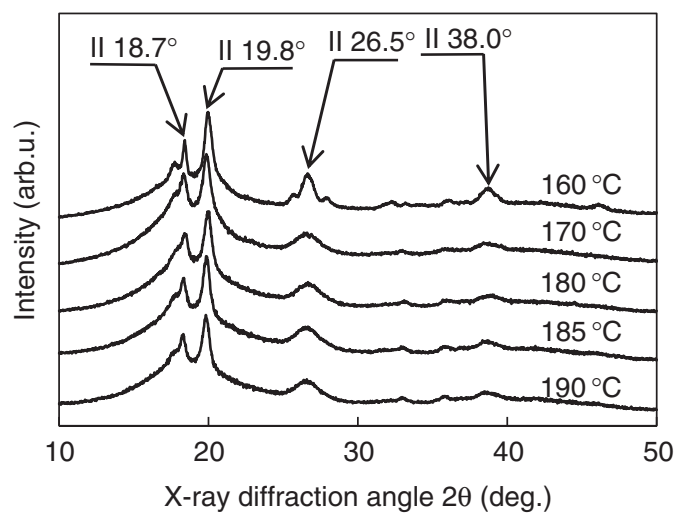

Figure 8 X-ray diffraction (XRD) spectra of F80 samples for each heattreatment temperature immediately after melting.

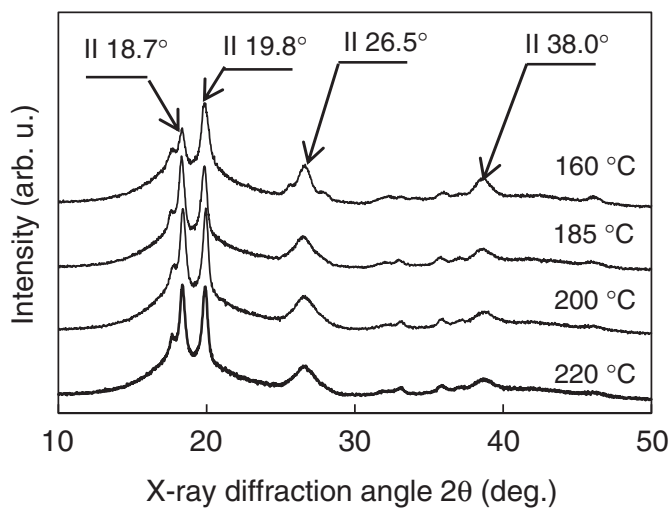

Figure 9 X-ray diffraction (XRD) spectra of F100 samples at each heattreatment temperature immediately after melting. 
Table 3 Relationships among PVDF crystalline structure, heattreatment temperature and blend ratio of PVDF/PMMA

Blend ratio with

PVDF/PMMA

The heat-treatment temperature just after the blend $\left({ }^{\circ} \mathrm{C}\right)$

\begin{tabular}{lccccccccc} 
& 160 & 170 & 180 & 185 & 190 & 200 & 210 & 220 \\
\hline F60 & II & II & II & $\mathrm{A}+(\mathrm{I})$ & $\mathrm{II}$ & - & - & - \\
F70 & II & II & $(\mathrm{I})+\mathrm{II}$ & I & I & $\mathrm{A}+(\mathrm{I}+\mathrm{II})$ & $\mathrm{A}+(\mathrm{I}+\mathrm{II})$ & - \\
F80 & II & $\mathrm{II}$ & $\mathrm{I}$ & $\mathrm{I}$ & $\mathrm{I}$ & - & - & - \\
F100 & $\mathrm{II}$ & - & - & $\mathrm{I}$ & - & $\mathrm{I}$ & - & $\mathrm{II}$ \\
\hline
\end{tabular}

Abbreviations: PMMA, poly(methylmethacrylate); PVDF, poly(vinilydene fluoride).

PVDF (form II) was obtained at all heat-treatment temperatures from the XRD and FT-IR spectra.

We examined the degree of crystallinity of F100 samples at each of the heat-treatment temperatures. The degree of crystallinity of heattreated F100 samples at $160,185,200$ and $220^{\circ} \mathrm{C}$ were $44 \%, 45 \%$, $43 \%$ and $42 \%$, respectively. Our examination of the degree of crystallinity of F100 samples at each temperature revealed only a slight difference. This result indicates that the degree of crystallinity did not change, although the heat-treatment temperatures were varied from 160 to $220^{\circ} \mathrm{C}$ for the F100 samples. Thus, we could not control the crystallization rate of the F100 sample by varying the heattreatment temperature. Pure PVDF crystallized very fast. For this reason, we assumed that the crystallization rate of PVDF simply could not be suppressed by controlling the heat-treatment temperature alone. Therefore, we concluded that PVDF (form I) cannot be developed from pure PVDF by simply controlling the heat-treatment temperature.

\section{Relationships among PVDF crystalline structure, heat-treatment temperature and blend ratios of PVDF/PMMA}

Table 3 indicates the relationships among PVDF crystalline structure, heat-treatment temperature and the blend ratio of PVDF/PMMA. PVDF crystalline structures in Table 3 differ with blend ratios of PVDF/PMMA and heat-treatment temperatures. This result is attributed to the different compatibilities between PVDF and PMMA, along with varying blend ratios of PVDF/PMMA. PVDF (high crystalline polymer) and PMMA (amorphous polymer) is a very rare combination that exhibits compatibility in a blend. Table 3 indicates that PVDF (form I) is obtained completely by the limited formation condition in F70, and the heat-treatment temperature is 185 or $190^{\circ} \mathrm{C}$. To explain this result, we assumed that PVDF polymer was formed by the structure of the PVDF (form I) according to decreasing the crystallization rate by the highest compatibility between PVDF and PMMA. We showed the highest compatibility of the F70 samples heat-treated at 185 and $190{ }^{\circ} \mathrm{C}$ by the following results. Their light transmittance became the highest without light scattering. They indicated $T_{\mathrm{g}}$ at the middle temperature on harmonizing with PVDF and PMMA. Furthermore, the melting point of PVDF decreased the most. No spherulites were observed in them using polarized light micrograph.

\section{CONCLUSIONS}

In this study, we analyzed the crystalline structure of F60, F70 and F80 samples at various heat-treatment temperatures. We obtained PVDF (forms I and II) owing to change in the blend ratios between PVDF and PMMA, and the heat-treatment temperature immediately after melting. The heat-treated F70 samples at 160 and $170{ }^{\circ} \mathrm{C}$ formed
PVDF (form II). PVDF (form II), including PVDF (form I), was obtained at $180^{\circ} \mathrm{C}$. PVDF (form I) was obtained at 185 and $190^{\circ} \mathrm{C}$, and amorphous structure including PVDF (form I and II) was obtained at 200 and $210^{\circ} \mathrm{C}$, respectively. In the F60, F80 and F100 samples, PVDF (form II) was obtained at all heat-treatment temperatures. We showed the highest compatibility of the F70 samples heat-treated at 185 and $190{ }^{\circ} \mathrm{C}$ by the following results. Their light transmittance became the highest without light scattering. They indicated $T_{\mathrm{g}}$ at the middle temperature on harmonizing with PVDF and PMMA. Furthermore, the melting point of PVDF decreased the most. No spherulites were observed in them using polarized light micrograph. We assumed that the crystallization rate of PVDF decreased with increasing compatibility between PVDF and PMMA. Therefore, the limited PVDF (form I) was obtained with the F70 samples heat-treated at 185 and $190^{\circ} \mathrm{C}$. Thus, we assumed that the crystallization rate of pure PVDF could not be controlled by the heattreatment temperature alone because pure PVDF crystallized so fast. Therefore, using the polymer blend method, we concluded that the control of PVDF crystallization based on sufficient compatibility between PVDF with PMMA, which has high compatibility against PVDF, is important for the production of PVDF (form I).

1 Tashiro, K., Kobayashi, M. \& Tadokoro, H. Structure and piezoelectricity of poly(vinylidene fluoride). Ferroelectrics 32, 167-175 (1981).

2 Tashiro, K., Kobayashi, M., Tadokoro, H. \& Fukada, E. Calculation of elastic and piezoelectric constants of polymer crystals by a point charge model: application to poly(vinylidene fluoride) form I. Macromolecules 13, 691-698 (1980).

3 Hasegawa, R., Kobayashi, M. \& Tadokoro, H. Molecular conformation and packing of poly(vinylidene fluoride). Stability of three crystalline forms and the effect of high pressure. Polym. J. 3, 591-599 (1972)

4 Hasegawa, R., Takahashi, Y., Chatani, Y. \& Tadokoro, H. Crystal structures of three crystalline forms of poly(vinylidene fluoride). Polym. J. 3, 600-610 (1972).

5 Nasir, M., Matsumoto, H., Minagawa, M., Tanioka, A., Danno, T. \& Horibe, H. Preparation of PVDF/PMMA blend nanofibers by electrospray deposition: effects of blending ratio and humidity. Polym. J. 41, 402-406 (2009).

6 Danno, T., Nasir, M., Matsumoto, H., Minagawa, M., Tanioka, A. \& Horibe, H. Fine structure of PVDF nanofiber fabricated by electrospray deposition. J. Polym. Sci. 46 558-563 (2008)

7 Nasir, M., Matsumoto, H., Minagawa, M., Tanioka, A., Danno, T. \& Horibe, H. Preparation of porous PVDF nanofiber from PVDF/PVP blend by electrospray deposition. Polym. J. 39, 1060-1064 (2007).

8 Nasir, M., Matsumoto, H., Minagawa, M., Tanioka, A., Danno, T. \& Horibe, H. Formation of $\beta$-phase crystalline structure of PVDF nanofiber by electrospray deposition: additive effect of ionic fluorinated surfactant. Polym. J. 39, 670-674 (2007)

9 Oshiro, H., Sato, T., Yamamoto, M., Kono, A., Horibe, H., Masunaga, H., Danno, T., Matsumoto, H. \& Tanioka, A. Crystal structure control of poly(vinylidene fluoride) using solvent casting. Kobunshi Ronbunsyu 67, 632-639 (2010).

10 Tokyo Kagaku Doujin. in Polymer Alloy -kiso to ouyou-, 143. Society Polymer Science edn (Tokyo Kagaku Doujin, Japan, 1981).

11 Paul, D. R. \& Newman, S. Polymer Blends, Ch. 8 Academic Press 1st edn (Elsevier, New York, 1978).

12 Nishi, T. Phase separation behavior of compatible polymer mixtures. Kobunshi 27 483-488 (1978).

13 Nishi, T. \& Wang, T. T. Melting point depression and kinetic effects of cooling on crystallization in poly(vinylidene fluoride)-poly(methyl methacrylate) mixtures. Macromolecules 8, 909-915 (1975).

14 Noland, J. S., Hsu, N. N. C., Saxon, R. \& Schmitt, J. M. Compatible high polymers poly(vinylidene fluoride) blends with homopolymers of methyl and ethyl methacrylate. Adv. Chem. Ser. 99, 15-18 (1971).

15 Patterson, G. D., Nishi, T. \& Wang, T. T. Brillouin scattering from poly(vinylidene fluoride)-poly(methyl methacrylate) mixtures. Macromolecules 9, 603-605 (1976)

16 Tokyo Kagaku Doujin. in Polymer Alloy -kiso to ouyou-, 98. Society Polymer Science edn (Tokyo Kagaku Doujin, Japan, 1981).

17 Hirata, Y., Uemura, S. \& Kotaka, T. Polymer blends of poly(vinylidene fluoride) and poly(methyl methacrylate): Phase separation behavior. Rep. Progr. Polym. Phys. Jpn 22, 177-180 (1979).

18 Hirata, Y. \& Kotaka, T. Phase separation and viscoelastic behavior of semicompatible polymer blends: poly(vinylidene fluoride)/poly(methyl methacrylate) system. Polym. J. 13, 273-281 (1981).

19 Tokyo Kagaku Doujin. in Polymer Alloy -kiso to ouyou-, 150. Society Polymer Science edn (Tokyo Kagaku Doujin, Japan, 1981). 
20 Fox, T. G. Influence of diluent and of copolymer composition on the glass temperature of a polymer system. Bull. Am. Phys. Soc. 1, 123-125 (1956).

21 Gordon, M. \& Taylor, J. S. Ideal copolymers and the second-order transitions of synthetic rubbers. i. non-crystalline copolymers. J. Appl. Chem. 2, 493-500 (1952).

22 Horibe, H. \& Baba, F. Relationship between UV transmittance and poly (vinylidene fluoride) crystal structures of poly (vinylidene fluoride)/poly (methyl methacrylate) blends after annealing. Kobunshi Ronbunsyu 57 (7), 403-411 (2000).

23 Horibe, H. \& Baba, F. PVDF/PMMA changes in crystal structures of PVDF in PVDF/PMMA blends heat-treated in several ways. Chem. Soc. Jpn 2, 121-126 (2000).

24 Horibe, H. \& Baba, F. PVDF/PMMA relationship between UV transmittance and compatibility of PVDF/PMMA blends. Chem. Soc. Jpn 2, 115-120 (2000).

25 Horibe, H. \& Taniyama, M. Acrylic-type resist removal using $532 \mathrm{~nm}$ laser pulses. J. Electrochem. Soc. 153, G119-G124 (2006).

26 Danno, T., Matsumoto, H., Nasir, M., Minagawa, M., Horibe, H. \& Tanioka, A. PVDF/ PMMA composite nanofiber fabricated by electrospray deposition: crystallization of PVDF induced by solvent extraction of PMMA component. J. Appl. Polym. Sci. 112 1868-1872 (2009).
27 Oshiro, H., Kono, A., Danno, T. \& Horibe, H. Crystal structure control of poly(vinylidene fluoride) (PVDF) in the blend films of PVDF and poly(methyl methacrylate) (PMMA) prepared by solvent casting. Kobunshi Ronbunsyu 69, 135-141 (2012).

28 Tashiro, K. \& Kobayashi, M. Calculation of limiting Young's moduli of rigid-rod polymers including poly-para-phenylene benzobisthiazole (PBT). Rep. Progr. Polym. Phys. Jpn 30, 119 (1987).

29 Matsushige, K. \& Takemura, T. Melting and Crystallization of poly(vinylidene fluoride) under high pressure. J. Polym. Sci. 16, 921-934 (1978).

30 Yu, S., Zheng, W., Yu, W., Zhang, Y., Jiang, Q. \& Zhao, Z. Formation mechanism of $\beta$ phase in PVDF/CNT composite prepared by the sonication method. Macromolecules 24, 8870-8874 (2009).

31 Takahashi, Y., Tadokoro, H. \& Odjima, A. Kink bands in form I of poly(vinylidene fluoride). Macromolecules 13, 1318-1320 (1980).

32 Bormashenko, Y., Pogreb, R., Stanevsky, O. \& Bormashenko, E. D. Vibrational spectrum of PVDF and its interpretation. Polym. Test. 23, 791-796 (2004).

33 Kobayashi, M., Tashiro, K. \& Tadokoro, H. Molecular vibrations of three crystal forms of poly(vinylidene fluoride). Macromolecules 8, 158-171 (1975). 